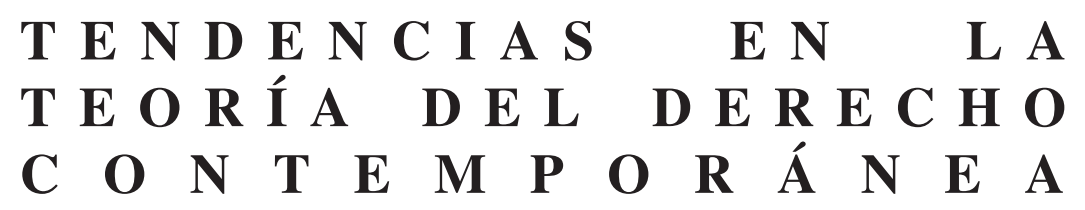




\section{TENSIONES CONCEPTUALES EN EL POSITIVISMO JURÍDICO}

Pablo E. Navarro

(CONICET, Argentina)

\section{Introducción}

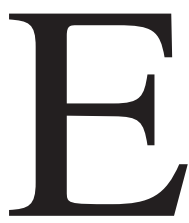

1 positivismo ha desempeñado un papel dominante en la filosofía contemporánea. En los últimos siglos, el positivismo produjo un impresionante conjunto de doctrinas acerca del lenguaje, la mente, el conocimiento y muchos otros temas filosóficos tradicionales. Mientras que el empirismo estuvo siempre asociado al desarrollo de las doctrinas positivistas, el último siglo fue testigo de un fuerte vinculo entre la consolidación del positivismo y el desarrollo de la lógica. La mejor expresión de esta alianza fue la emergencia del Positivismo Lógico en el horizonte filosófico. La influencia de este movimiento difícilmente puede ser negada, y es probable que su contribución a la filosofía perdure por largo tiempo. Desde sus comienzos, el Positivismo Lógico fue severamente criticado. Algunas veces, las críticas surgían de interpretaciones equivocadas, o de la exageración de la importancia del rechazo de algunas de sus tesis marginales. Por ejemplo, algunas veces se impugnaba al Positivismo Lógico por su supuesto compromiso con posiciones moralmente censurables. Así, el rechazo del carácter cognoscitivo del discurso práctico ha sido considerado como un síntoma de nihilismo y corrupción moral. En este sentido, Rudolf Carnap afirma ${ }^{1}$ :

I have often found philosophers who, in their criticism of our conception, ascribe to the problem of the logical nature of value statements an exaggerated practical significance. According to these critics, to deny to value statements the status of theoretical assertions and thereby the possibility of demonstrating their validity must necessarily lead to immorality and nihilism.

Sin embargo, otras críticas estaban dirigidas a su núcleo conceptual, y amenazaban el proyecto positivista por completo (e.g. la demarcación entre

\footnotetext{
${ }^{1}$ Rudolf Carnap: 'Intellectual Autobiography' en The Philosophy of Rudolf Carnap, The Library of Living Philosophers, Paul Schilpp, ed., p.81 ( La Salle, Illinois: Open Court, 1963)
} 
ciencia y metafísica, la distinción entre enunciados analíticos y sintéticos). Más allá de la relevancia de estas críticas, y de otras circunstancias históricas que fagocitaron la desaparición de este movimiento, hay que subrayar que la decadencia del positivismo lógico fue principalmente el resultado de refutaciones y críticas internas. En este sentido, uno de los lideres de la filosofía analítica contemporánea, Georg Henrik von Wright, ha señalado²:

It is nowadays commonplace to declare logical positivism dead and gone. It should be remembered, however, that the movement was conquered and superseded largely thanks to self-criticism generated in its own circle. This combination of self-destruction with self-development is perhaps unique in the history of thought. At least I know no comparable case.

Sin embargo, en contra de lo que concluye von Wright, el último siglo también ha sido testigo de la consolidación y crisis de otra importante doctrina positivista: el positivismo jurídico. Al igual que el positivismo lógico, el positivismo jurídico contemporáneo fue modelado y defendido por filósofos brillantes, y su contribución a nuestra comprensión de la naturaleza del derecho ha sido significativa. Aunque algunos positivistas jurídicos, por ejemplo Alf Ross, han sido positivistas lógicos, ésta es sólo una conexión contingente, y es necesario distinguir cuidadosamente entre ambos tipos de positivismos $^{3}$. Pero, aun cuando ellos son claramente diferentes, es interesante destacar que en ambos casos, el cambio y evolución de sus tesis ha sido, en gran medida, el resultado de discusiones internas al proyecto positivista. Estas discusiones muestran claramente que las tesis centrales enunciadas por algún positivista son, con cierta frecuencia, rechazadas o consideradas incoherentes por otros positivistas. Por ejemplo, Alf Ross rechazó el concepto de validez como fuerza vinculante de las normas defendido por Kelsen, y acusó a este último de ser un 'cuasi-positivista', que era una versión degenerada del iusnaturalismo. Otro ejemplo es la queja de Hart contra Raz, cuando este último rechaza la tesis semántica del positivismo. Esta tesis afirma que ciertas expresiones del vocabulario normativo, e.g. 'derechos', 'obligaciones' etc, tienen distinto significado en contextos jurídicos y morales. Según Hart, el rechazo de la tesis semántica conduce a Raz a 'ofrecer una rama de olivo a aquellos que sostienen que hay una importante conexión conceptual entre derecho y moral'4.

\footnotetext{
${ }^{2}$ Georg Henrik von Wright: 'Logic and Philosophy in the 20th Century' en The Tree of Knowledge and Other Essays, p. 16 (Leiden-New York-Köln: E.J. Brill, 1993)

${ }^{3}$ Frederick Schauer, 'Positivism as Pariah' en The Autonomy of Law. Essays on Legal Positivism, Robert P. Georg, editor, nota 6. p.p. 48-49 (Oxford: Oxford University Press, 1996)

${ }^{4}$ H.L.A. Hart, 'Positivism and the Separation of Law and Moral' en Essays in Jurisprudence and Philosophy, pp. 9-10 (Oxford: Oxford University Press, 1983)
} 
Estas discusiones entre los lideres de las concepciones positivistas son consideradas, a menudo, como un síntoma de que el positivismo jurídico colapsa necesariamente en posiciones antipositivistas. Por ejemplo, Roger Shiner comienza su libro Norm and Nature. The Movements of Legal Thought $t^{5}$ con el estudio de una versión mínima del positivismo clásico ${ }^{6}$. Luego, Shiner considera si una versión sofisticada del positivismo -que él atribuye principalmente a H.L.A. Hart- puede mitigar algunas deficiencias del positivismo simple, y concluye que el resultado inevitable de tomar seriamente las intuiciones del positivismo sofisticado ha conducido a la teoría jurídica a una posición antipositivista ${ }^{7}$. La transición desde el positivismo simple hacia el positivismo sofisticado parece necesario para superar importantes problemas de las formulaciones clásicas del positivismo, e.g. la naturaleza de las obligaciones jurídicas. Sin embargo, no es claro que el positivismo sofisticado pueda proporcionar una respuesta satisfactoria a estos problemas. Por esta razón, Beyleveld and Browsword señalan que ${ }^{8}$

... modern legal positivists, in keeping with the spirit of Austinian jurisprudence, maintain that there is no necessary connection between either legal validity, and moral validity, or between legal obligation and moral obligation. In short, law is to be understood as normative but not morally prescriptive. The central contention of our paper is that this modern version of Legal Positivism... is incoherent.

En resumen: existiría una tensión interna al programa positivista, que puede resumirse de la siguiente manera. Las tesis centrales del positivismo jurídico clásico, e.g. Austin, Bentham, son inadecuadas para dar cuenta de la complejidad de nuestras prácticas jurídicas, pero el intento de superar estas dificultades conduce a adoptar tesis incompatibles con la doctrina positivista.

Al igual que el positivismo lógico, la dinámica interna del positivismo jurídico parece conducir a posiciones antipositivistas. En otras palabras, el positivismo jurídico se habría autodestruido. Por razones de simplicidad, esta conclusión será denominada 'la tesis de la autodestrucción'. En este trabajo, me interesa analizar si de las premisas que definen al positivismo jurídico se puede extraer un vinculo necesario entre derecho y moral. Aun

\footnotetext{
5 Roger Shiner, Norm and Nature. The Movements of Legal Thought (Oxford: Oxford University Press, 1992)

${ }^{6}$ Shiner caracteriza este tipo de positivismo como 'positivismo simple', y considera a John Austin como su principal representante. See, Roger Shiner, Norm and Nature. The Movements of Legal Thought, op. cit., pp. 19-40.

${ }^{7}$ Roger Shiner, Norm and Nature. The Movements of Legal Thought, op. cit., p. 324

${ }^{8}$ Deryck Beyleveld and Roger Brownsword, 'Normative Positivism: The Mirage of the Middle Way' en Oxford Journal of Legal Studies, 9 (1989), p.463.
} 
cuando no sea posible defender esta conclusión, es importante destacar que los argumentos necesarios para rechazarla nos permiten comprender mejor la naturaleza del derecho y la teoría jurídica. En particular, consideraré sólo tres argumentos que intentan señalar que el núcleo del positivismo jurídico encierra tesis que inevitablemente conducen a posiciones antipositivistas. En primer lugar, examinaré si los positivistas deben admitir que las normas jurídicas poseen alguna fuerza moral. En segundo lugar, analizaré si la relación entre identificación de las normas jurídicas y el proceso de interpretación del derecho compromete a aceptar la unión entre derecho y moral. Finalmente, también abordaré el problema de la relación entre justificación jurídica y actitudes morales'.

La pregunta central de este trabajo puede ser resumida de la siguiente manera: ¿es verdad que el positivismo jurídico contemporáneo se ha autodestruido?. Para responder esta pregunta son necesarias algunas clarificaciones y distinciones preliminares.

\section{Tesis centrales e incidentales}

El debate entre diferentes concepciones del positivismo jurídico es tan antiguo como las reflexiones teóricas acerca de sus rasgos centrales. En parte, las diferentes maneras de caracterizar al positivismo se refleja en la 'inflación' de distinciones que se han multiplicado en los últimos años. Así, por ejemplo, es frecuente distinguir entre positivismo positivo y negativo, positivismo presuntivo y formalismo; positivismo simple y sofisticado; positivismo 'blando' (soft positivism) y positivismo duro, positivismo incluyente y positivismo excluyente. Todas estas distinciones intentan articular de la mejor manera las tesis centrales que caracterizan al positivismo jurídico. Sin embargo, no estoy convencido de que esta multiplicación de distinciones muestre refinamiento antes que confusión conceptual. Creo, sin embargo, que en entre estas distinciones, a menudo, se esconden algunas tesis que son extrañas al positivismo jurídico (e.g, la fuerza moral del derecho o la dimensión normativa de la validez jurídica) y por ello sus conclusiones pueden generar aun más confusión. La falta de una adecuada discusión sobre estos presupuestos tiene como consecuencia que el positivismo parece ofrecer una reconstrucción incoherente de nuestras prácticas jurídicas. Por ello, mi propósito se limita a abordar la cuestión acerca de si el positivismo jurídico es un proyecto auto-destructivo, antes que avanzar sobre las diferencias entre diferentes versiones del positivismo jurídico.

\footnotetext{
${ }^{9}$ En general, me concentraré principalmente en algunas tesis defendidas por H.L.A. Hart, pero debe quedar claro que no me interesa una exégesis de su pensamiento o un comentario sobre la abundante bibliografía disponible sobre esta versión del positivismo jurídico.
} 
Algunas veces la tesis de la autodestrucción parece inevitable sólo porque no se distingue claramente entre las tesis centrales que definen al positivismo jurídico y algunas tesis incidentales que han sido defendidas en ciertas ocasiones por algunos teóricos positivistas. Este tipo de confusión ha sido puesta de manifiesto por Hart hace ya más de cuarenta años ${ }^{10}$. Según Hart, la tesis de la separación entre derecho y moral es parte del núcleo conceptual del positivismo jurídico. Sin embargo, no siempre es claro qué alcance tiene esta tesis en las diferentes doctrinas positivistas. Algunas veces, por ejemplo, se sostiene que la separación conceptual entre derecho y moral implica que la definición del concepto de derecho tienen que ser valorativamente neutral, o bien que el derecho no tiene necesariamente valor moral positivo ${ }^{11}$. Aunque interesantes, estas versiones de la tesis de la separación no capturan el contenido de las formulaciones clásicas proporcionadas por Austin y Bentham. Para ellos, la falta de una clara separación entre derecho y moral otorgaba plausibilidad a las posiciones reaccionarias o anarquistas, diluyendo de esta manera la autoridad del derecho en juicios individuales acerca de lo que se debe hacer o no hacer. El anarquista señala las discrepancias entre lo que las autoridades exigen y sus convicciones como prueba de que el derecho, en realidad, no impone las obligaciones que establecen las autoridades. El reaccionario, por el contrario, señala a la coincidencia entre sus convicciones y lo que disponen las autoridades como prueba de la inutilidad o ilegitimidad de los cambios sociales. Parece claro, entonces, que la posibilidad de discrepancia entre aquello que disponen las normas jurídicas y las convicciones morales de los individuos se encuentra en la base del reconocimiento de la autoridad del derecho.

El significado central de la tesis de la separación ha sido resumido por Hart de la siguiente manera ${ }^{12}$ :

...in the absence of an expressed constitutional or legal provision, it could not follow from the mere fact that a rule violated standards of morality that it was not a rule of law; and conversely, it could not follow from the mere fact that a rule was morality desirable that it was a rule of law.

${ }^{10}$ H.L.A. Hart, 'Positivism and the Separation of Law and Moral', en Essays in Jurisprudence and Philosophy, op. cit., pp. 56-62.

11 Véase, Klaus Fusser, 'Farewell to Legal Positivism. The Separation Thesis Unravelling' en The Autonomy of Law. Essays on Legal Positivism, op. cit. pp. 119-162. También, David Lyons, 'Moral Aspects of Legal Theory' en Moral Aspects of Legal Theory, pp. 64-101. En este trabajo, Lyons atribuye a Raz una extraña justificación de la tesis de la separación (p. 92). Raz ha replicado en 'Authority, Law and Morality' en Ethics in the Public Domain. Essays in the Morality of Law and Politics, p. 219 (Oxford: Oxford University Press, 1994).

12 H.L.A. Hart, 'Positivism and the Separation of Law and Moral', en Essays in Jurisprudence and Philosophy, op. cit., p. 55. 
Esta tesis, que algunas veces es condensada en el slogan 'no hay que confundir el derecho que es y el que debe ser', ha sido con frecuencia malinterpretada o confundida con otras tesis incidentales. Por ejemplo, John Austin, que claramente adhería a la tesis de la separación, también sostenía que el derecho era esencialmente el mandato (órdenes) de un soberano. Esta tesis imperativista, sin embargo, no define al positivismo jurídico, y por esta razón puede ser considerada como una tesis incidental. Según Hart, una fuente de confusión al momento de criticar la tesis de la separación es la creencia de que la falsedad de la tesis incidental implica que las tesis centrales del positivismo también son falsas. Por ejemplo, Salmond rechaza el imperativismo de la teoría de Austin ya que en esta última concepción la noción de derechos (rights) queda sin analizar. Los derechos no pueden ser identificados con órdenes, y por esta razón, Salmond parece creer que la única alternativa disponible es identificar a los derechos jurídicos con expectativas morales de los miembros de una comunidad. Así, Salmond concluye que las normas jurídicas -en tanto que atribuyen derechos a los individuos- tienen que estar necesariamente conectadas con la moral. De esta manera, el rechazo de la tesis incidental del imperativismo conduce a negar la tesis central de la separación entre derecho y moral. Sin embargo, una vez que se detecta la confusión entre aquello que define al positivismo jurídico y otras doctrinas marginales, la ilusión de la autodestrucción puede ser evitada con facilidad.

No intentaré defender el imperativismo de Austin. Tampoco pondré en duda que la tesis de la autodestrucción, como Hart señaló acerca de otras doctrinas paradójicas acerca de la naturaleza del derecho ${ }^{13}$, puede resultar esclarecedora. Únicamente intento rechazar una cierta interpretación de la tesis de la autodestrucción, i.e. algunas tesis incidentales pueden producir incoherencias en las doctrinas positivistas y tienen que ser rechazadas. Si la tesis de la autodestrucción se limitase a señalar este dato, entonces no hay dudas de que ella debería ser aceptada sin mayor discusión. Esta tesis sería verdadera, pero más bien trivial y no aporta nada relevante a la discusión sobre los méritos o defectos del positivismo jurídico. Esta interpretación torna inofensiva a la tesis de la autodestrucción. El mensaje intuitivo de esta tesis es el siguiente: si fuese verdadero que el positivismo se autodestruye, entonces deberíamos rechazar no sólo ciertas doctrinas marginales defendidas por los positivistas sino al positivismo jurídico por completo. Pero, para defender esta conclusión, es necesario proporcionar algún argumento general que conecte algunas de las tesis centrales del positivismo con algunas

${ }^{13}$ H.L.A. Hart, The Concept of Law, segunda edición, Joseph Raz and Penélope Bulloch, editores, p. 2 (Oxford: Oxford University Press, 1994) 
conclusiones inaceptables. Por consiguiente, es necesario considerar otras posibles versiones de la tesis de la autodestrucción.

\section{Positivismo conceptual y positivismo ideológico}

Como es bien conocido, la tesis de la separación conceptual entre derecho y moral es esencial para el positivismo jurídico. Otra tesis central es la tesis de las fuentes sociales, que afirma que la existencia del derecho depende exclusivamente de hechos sociales complejos ${ }^{14}$. Ambas tesis definen al positivismo conceptual (también conocido como positivismo metodológico o positivismo como approach), que sostiene que el derecho se identifica únicamente a partir de circunstancias fácticas. En otras palabras: para describir las normas jurídicas, un teórico del derecho no necesita evaluar la coincidencia entre normas jurídicas y principios de moralidad y justicia.

Los problemas para el positivismo jurídico parecen surgir de la influencia de una doctrina recurrente que atribuye fuerza moral a las normas jurídicas. Según esta doctrina, que Norberto Bobbio ha denominado Positivismo Ideológico ${ }^{15}$, las normas jurídicas válidas proveen razones morales para justificar acciones o decisiones. El positivista ideológico no se limita a la descripción de las normas jurídicas, sino que también adhiere a lo que ellas disponen. El positivismo conceptual no niega que las normas jurídicas puedan ser siempre justas o moralmente correctas, pero señala que su status jurídico, i.e. su validez no depende de la satisfacción previa de un criterio moral. Al respecto, Jules L. Coleman afirma ${ }^{16}$ :

Suppose that, in every possible legal system, the community's law completely coincide with what was morally correct. This would show only that law and morality are everywhere coextensive, not that they are cointensional...It is the intensional (conceptual) relationship between law and morality that counts. Even if law and morality coincide, what makes something a moral principle is the fact that it is so in the correct theory of morality; and what makes something law is the fact that it satisfies the conditions of legality in the rule of recognition.

Por el contrario, la conexión que señala el positivismo ideológico significa que el derecho siempre tiene fuerza moral, incluso si la aplicación de las normas jurídicas parece conducir a un resultado injusto. En otras palabras, la no aplicación de las normas válidas siempre involucraría una falta moral. Según el positivismo ideológico, las normas válidas merecen respe-

${ }^{14}$ Una versión refinada de esta tesis puede encontrarse en Joseph Raz, The Authority of Law, pp. 41-43 (Oxford: Oxford University Press, 1979).

15 Norberto Bobbio, El Problema del Positivismo Jurídico (Buenos Aires: Eudeba, 1965)

16 Jules L. Coleman, 'Rules and Social Facts' en Harvard Journal of Law \& Public Policy, 14 (1991), p. 723. 
to moral por el mero hecho de emanar de autoridades eficaces. Como señala Carlos Nino ${ }^{17}$,

Ideological positivism holds that a legal system identified, as conceptual positivism recommends by factual features, such as having been enacted by those who possess a monopoly of coercion has an inherent moral appeal and should be applied and endorsed whatever its content.

Es ciertamente lamentable que la misma palabra, i.e. 'positivismo' sea aplicada a doctrinas tan diferentes. Sin embargo, ¿esta ambigüedad es solo producto de un accidente del lenguaje?. Por el contrario; ¿sería posible mostrar una conexión más fuerte entre ambos positivismos? Una respuesta afirmativa a este ultimo interrogante se encuentra en la base de la tesis de la autodestrucción. Cuando advertimos que uno de los principales exponentes del positivismo jurídico, Jeremy Bentham, señalaba que el lema de un buen ciudadano en un Estado de Derecho es 'Obedecer puntualmente, censurar libremente', podemos concluir que la tesis de la autodestrucción merece un cuidadoso análisis. Después de todo, como señalamos anteriormente, parte de los objetivos de Bentham era dar cuenta de la autoridad del derecho, y distinguir sus exigencias de los juicios individuales acerca de la corrección o incorrección de las normas jurídicas. En otras palabras: si el derecho no tuviese relevancia práctica, entonces carecería de sentido la insistencia en distinguir lo que disponen las normas jurídicas de aquello que exige la moral. La razón es simple: si el derecho no imponen obligaciones, entonces no es necesario recurrir a razones últimas (i.e. razones morales) a efectos de mostrar que no se debe hacer lo que las autoridades exigen.

Asumir la relevancia práctica del derecho es lo que otorga plausibilidad a la tesis de la autodestrucción. Esta relevancia práctica significa que el derecho ofrece razones específicas para la acción. Mientras que para los positivistas clásicos, estas razones surgen principalmente de la amenaza y probabilidad de castigos, los positivistas contemporáneos han rechazado esta caracterización. Según Kelsen, Hart, Raz, MacCormick etc. es necesario explicar la normatividad del derecho mediante otra estrategia conceptual. Pero, estas estrategias -se argumenta desde posiciones antipositivistas- conducen a revelar una conexión conceptual entre derecho y moral. En este sentido, la tesis de la autodestrucción señala que el positivismo afirma y niega al mismo tiempo conexiones conceptuales entre las exigencias del derecho y nuestros compromisos morales. La tesis de la autodestrucción, entonces, señala que el positivismo jurídico no puede rechazar la fuerza moral de las normas jurídicas. En general, el argumento es que, para los positivistas, el

\footnotetext{
${ }^{17}$ Carlos Nino, The Ethics of Human Rights, p. 11 (Oxford: Oxford University Press, 1991)
} 
derecho es el resultado de decisiones sociales específicas. Nada conecta conceptualmente a estas decisiones con lo que se debe hacer, ya que las decisiones de los legisladores pueden resultar (y de hecho a menudo resultan) erróneas. Por consiguiente, si además el positivista sostiene que el derecho debe ser obedecido puntualmente, o que las normas jurídicas tienen relevancia práctica, entonces debe existir alguna premisa moral que confiere fuerza vinculante a las exigencias de las autoridades jurídicas.

\section{Validez y pertenencia a un sistema jurídico}

Según hemos visto, el positivismo ideológico es una versión del positivismo que asume que las normas jurídicas imponen exigencias morales. Por consiguiente, a primera vista, la tesis de la autodestrucción destacaría un nexo entre el positivismo conceptual y el positivismo ideológico. Sin embargo, como veremos a continuación, tal nexo parece ser sólo una confusión. Las diferencias entre ambos tipos de positivismo pueden ser claramente comprendidas cuando se recuerda la crítica de Gustav Radbruch y la réplica de Hart. Según Radbruch, el slogan 'Gesetz ist Gesetz', que él atribuye al positivismo jurídico, contribuyó a los horrores del Nazismo. Por su parte, Hart responde ${ }^{18}$ :

For everything he says is really dependent upon an enormous overvaluation of the importance of the bare fact that a rule may be said to be a valid rule of law, as if this, once declared, was conclusive of the final moral question: 'Ought this rule to be obeyed?'. Surely the truly liberal answer to any sinister use of the slogan 'law is law' or of the distinction between law and morals is 'Very well, but that does not conclude the question. Law is not morality; do not let it supplant morality'.

Según parece desprenderse de esta afirmación, Hart considera que los enunciados de validez carecen de relevancia práctica. Conforme a esta conclusión, del enunciado acerca de la validez de una cierta norma jurídica sólo se sigue que esa norma forma parte del sistema jurídico.

Un sistema normativo es un conjunto con una relación especifica entre sus elementos. Las relaciones entre los elementos del conjunto definen la estructura del sistema normativo (i.e. sistemas estáticos o dinámicos), y suministran sus criterios de pertenencia. En general, los juristas elaboran estos criterios de pertenencia a partir de dos relaciones entre normas: legalidad y deducibilidad. Al mismo tiempo, estos criterios son también reconocidos como criterios de validez de las normas jurídicas. En este sentido, la validez de una norma se identifica con la pertenencia a un sistema normativo. Conforme al criterio de legalidad, una norma es válida si y sólo ha sido

${ }^{18}$ H.L.A. Hart, 'Positivism and the Separation of Law and Moral', op. cit., p. 75. 
promulgada por una autoridad competente, mientras que según el criterio de deducibilidad, una norma es válida en un sistema cuando se deriva lógicamente de otras normas del sistema.

A efectos de evitar circularidad o regreso al infinito, es preciso admitir que al menos una norma del conjunto normativo no satisface las relaciones sistemáticas. Estas normas cuya pertenencia al conjunto no puede establecerse a partir de la satisfacción de esas relaciones son las normas independientes del sistema. Las restantes normas, i.e. las normas dependientes sólo forman parte del conjunto en tanto que satisfacen ciertas relaciones con otras normas (independientes o dependientes) del sistema.

Las normas que satisfacen el criterio de deducibilidad son normas derivadas en el sistema jurídico, y -salvo casos de redundancia- no han sido expresamente formuladas por la autoridad normativa. En este sentido se diferencian claramente de otras normas, cuya pertenencia al sistema está intrínsecamente relacionada con los actos expresos de las autoridades. Una doctrina positivista consistente con la tesis de las fuentes sociales no puede admitir que todas las normas de un sistema jurídico carezcan de formulación expresa. Como ha demostrado Hart, los casos paradigmáticos de sistema jurídico presentan una unión de distintas reglas, i.e. reglas primarias y secundarias. Sin esta compleja estructura social, careceríamos de instancias centrales de aplicación de la expresión 'sistema jurídico'. Entre las reglas secundarias del sistema encontramos a las reglas de cambio, que permiten modificar deliberadamente el status normativo de ciertas acciones. De esta manera, alguna forma de legislación, (i.e. regulación expresa de situaciones genéricas) es necesaria para la existencia de un sistema jurídico.

La moraleja de este enfoque sería que, mientras que el criterio de legalidad está conceptualmente relacionado con nuestra noción de sistema jurídico, no es claro que exista un argumento similar para defender, dentro de las doctrinas positivistas, a la necesariedad del criterio de deducibilidad. Sin ese argumento, la existencia de normas derivadas en un sistema jurídico dependería exclusivamente de las prácticas contingentes de reconocimiento de validez en una cierta comunidad ${ }^{19}$. De esta manera, las normas derivadas serían más 'dependientes' que otras normas, por dos razones. Por una parte, su pertenencia al sistema sería contingente, mientras que la existencia de las normas expresamente formuladas por las autoridades está conceptualmente conectadas a la noción de sistema jurídico. Por otra parte, mientras que las

${ }^{19}$ Esto no significa que las normas formuladas sean 'normas necesarias' o algo por el estilo. Sólo intento señalar que la existencia de un sistema jurídico está ligada a las actitudes crítico-reflexivas de aceptación de que ciertas personas o instituciones pueden modificar deliberadamente las normas del sistema jurídico. 
normas expresamente formuladas pueden ser independientes o dependientes en el sistema jurídico, las normas derivadas son siempre normas dependientes.

De este enfoque se siguen tres consecuencias importantes:

a) El carácter descriptivo de los enunciados de validez. Un enunciado de validez describe la existencia de ciertas relaciones entre normas de un determinado sistema jurídico.

b) La relatividad de los enunciados de validez. La verdad de los enunciado de validez son relativos a determinados conjuntos de normas, y por consiguiente, el enunciado que afirma que la norma $\mathrm{Nj}$ es válida puede ser verdadero cuando se toma como referencia a un sistema $\mathrm{Sj}$, pero puede ser falso si se tomase como referencia a otro sistema Sk.

c) El trasfondo empírico de los enunciados de validez. Los enunciados de validez pueden ser analizados, en última instancia, como afirmaciones acerca de ciertos hechos sociales complejos, e.g. la promulgación de ciertas normas.

Conforme a esta reconstrucción sistemática de la validez de las normas jurídicas es fácil comprender que la afirmación de que una norma es válida no implica a ningún juicio práctico. Afirmar que una norma pertenece a un sistema jurídico sólo establece que un determinado objeto forma parte de un cierto conjunto. Este es un enunciado de hecho, y no un enunciado normativo. Si se admite que existe un abismo lógico entre enunciados de hecho y enunciados normativos, entonces ninguna conclusión normativa puede seguirse del 'hecho de que pueda señalarse que una norma es una norma jurídica válida'. El positivismo, tal como es definido a partir de la tesis de la separación y la tesis de las fuentes sociales, no se compromete a reconocer relevancia práctica a las normas jurídicas. Esto significa que podemos describir el hecho de que una norma sea válida e informar acerca del status jurídico de ciertas acciones o estados de cosas sin adherir al contenido de sus prescripciones.

Sin embargo, la reconstrucción de Hart no extrae todas estas consecuencias. Así, pueden señalarse, al menos, dos dificultades.

En primer lugar, en The Concept of Law, Hart distingue entre los enunciados internos y las afirmaciones acerca de que una norma satisface los criterios de validez establecidos por la regla de reconocimiento. Luego, a pesar de que en su réplica a Radbruch insinúa que los enunciados de validez no expresan compromisos prácticos, sostiene que los enunciados de validez no se pueden reducir a afirmaciones acerca de la pertenencia de una norma al sistema. Esta 'reducción' de los enunciados de validez ocultaría el carácter interno de los juicios de validez. Más adelante analizaré con algún detalle el problema de los enunciados internos (sección V). Ahora sólo es pre- 
ciso indicar que la característica principal de estos enunciados es que expresan una actitud crítica-reflexiva por parte del aceptante de una norma. De esta manera, aunque en su réplica a Radbruch, Hart parece negar relevancia práctica a los enunciados de validez, su estrategia conceptual se ve empañada por la falta de una clara distinción entre un uso normativo y un uso descriptivo de 'validez'. Este defecto ha sido posteriormente advertido por Hart. De esta manera, él señala ${ }^{20}$ :

I drew a distinction between internal statements which manifest their author's acceptance of a rule and external statements which simply state or predict certain regularities of behaviour whether it is rule-governed or not. But I wrongly wrote as if the normative vocabulary of 'ought', 'must', 'obligation', 'duty' were only properly used in such internal statements. This is a mistake, because, of course, such terms are quite properly used in other forms of statements, and particularly in lawyers' statements of legal obligations or duties describing the contents of a legal system (whether it be their own or an alien system) whose rules they themselves in no way endorse or accept as standards of behaviour.

En segundo lugar, en su argumento contra Radbruch, Hart sólo niega explícitamente que las normas jurídicas sean respuestas finales a preguntas morales, pero su afirmación deja abierta la posibilidad de adscribir alguna relevancia moral no-concluyente a las normas jurídicamente válidas. Por consiguiente, ¿podríamos decir que las normas válidas son moralmente vinculantes, aun si ellas no proporcionan una respuesta moral concluyente?

Finalmente, en The Concept of Law, Hart sostiene que en la noción de aplicar una regla general encontramos el germen, al menos, de la justicia ${ }^{21}$. Por ello señala que en la misma noción de regular el comportamiento mediante normas generales, se encuentra un valor formal que nos impide considerar al derecho de una manera neutral. Esto sugiere una concesión a las tesis antipositivistas ya que, por la misma razón, Hart debe admitir que en la no-aplicación de las normas jurídicas válidas encontramos, al menos, el germen de la injusticia. Esta conclusión, que surge de ciertas propiedades de las normas y rasgos formales de la noción de justicia, parece incompatible con el positivismo jurídico. No abordaré en este trabajo la cuestión de si la noción formal de justicia y la regla que exige tratar a casos iguales de igual manera es compatible con el positivismo jurídico. Sólo deseo recordar que, como Kenneth I. Winston ha señalado ${ }^{22}$,

... Hart's argument yields the following rather curious result: If it is part of the meaning of a legal system that it consists of general rules, and if the notion

${ }^{20}$ H.L.A. Hart, 'Introduction' en Essays in Jurisprudence and Philosophy, op. cit., p. 14.

${ }^{21}$ H.L.A. Hart, The Concept of Law, op. cit., p. 206.

22 Kenneth I. Winston, 'On Treating Like Cases Alike' en California Law Review 62 (1974), p. 3. 
of law consisting of general rules embodies a certain moral principle (a principle of justice), then any system of governance that does not embody this moral principle is not a legal system... Thus in drawing out the implications of Hart's argument, I appear to have confirmed a suspicion that legal positivists neglect the consequences of their occasional avowals that legal and moral standards intersect. There is a strain in Hart's argument, it seems, pulling him toward a form of natural law theory, or at least, pulling him away from legal positivism...

En la sección siguiente, analizaré las consecuencias que tiene para el programa positivista el abandono de una nítida separación entre descripción y prescripción, o entre conocimiento y adhesión a las normas jurídicas.

\section{Validez y fuerza vinculante}

A diferencia de la reconstrucción del concepto de validez ofrecida en la sección anterior, un enfoque tradicional de la validez de las normas jurídicas insiste en que los enunciados de validez no describen que una norma pertenece a un sistema normativo sino que ellos indican que la norma en cuestión debe ser obedecida y aplicada. Según este punto de vista, las normas válidas tienen fuerza vinculante ${ }^{23}$. Éste es un concepto normativo de validez. Por esta razón, aun si todas las normas que pertenecen al sistema jurídico (y sólo ellas) fuesen vinculantes, ello no significaría que la pertenencia al sistema y la fuerza vinculante son la misma propiedad. No es claro, sin embargo, a que se refiere la expresión 'fuerza vinculante' y no pocas veces se ha sugerido que esta característica de las normas jurídicas es indistinguible de su fuerza moral. Otras veces se afirma que el derecho posee una 'fuerza específica', es decir, una dimensión normativa peculiar, que no puede ser reducida a su eventual valor moral. En esta sección, abordaré principalmente la relación entre validez y fuerza moral. Por consiguiente, se impone responder claramente a la siguiente cuestión: ¿puede un positivista aceptar que las normas jurídicas válidas tienen fuerza moral?

Las normas jurídicas válidas, a diferencia de aquellas que son inválidas, siempre ofrecerían razones para actuar, aun cuando ellas nunca fuesen razones morales concluyentes. Esta reconstrucción de la noción de validez jurídica es una forma de positivismo ideológico ya que atribuye relevancia moral a las normas válidas por el mero echo de formar parte de un sistema jurídico vigente en una cierta comunidad. Este tipo de ideología es algunas veces disimulada por complejas doctrinas acerca de la autoridad del derecho o de las creencias morales de las autoridades normativas. Por ejemplo, John Finnis considera que incluso las normas promulgadas por un dictador

\footnotetext{
${ }^{23}$ Joseph Raz, 'Legal Validity' en The Authority of Law, p. 150 (Oxford: Oxford University Press, 1979).
} 
o un conquistador son moralmente vinculantes ${ }^{24}$. Esta ideología también está presente en, por ejemplo, la reconstrucción de Philp Soper de los deberes morales prima facie de los esclavos hacia sus propietarios siempre que estos últimos crean sinceramente que sus acciones están moralmente justificadas. Es claro que ni Finnis ni Soper son partidarios del positivismo jurídico, pero sus argumentos son útiles para comprender qué se sigue de un concepto normativo de validez.

Es destacable el hecho de que muchos positivistas contemporáneos aceptan que las normas jurídicas poseen (algún grado de) valor moral, y sólo debaten acerca de la naturaleza concluyente o prima facie de las obligaciones que imponen estas normas. Este punto de vista es usualmente asociado a la explicación de la normatividad del derecho. En los debates de las últimas décadas, esta propiedad parece constituir un límite conceptual, que cualquier teoría adecuada del derecho debe satisfacer, es decir, una teoría del derecho que no explique la normatividad sería, por ese sólo motivo, una propuesta conceptual inadecuada. Sin embargo, cuarenta años atrás, las cosas eran diferentes, y las razones para este cambio en la agenda teórica aun no han sido satisfactoriamente explicadas. Así, en 1961, Alf Ross sostuvo enfáticamente que un concepto normativo de validez era ajeno al positivismo jurídico. Su principal argumento, dirigido contra la Teoría Pura del Derecho de Hans Kelsen, era el siguiente ${ }^{25}$ : cuando admitimos que las normas jurídicas válidas deben ser obedecidas, también debemos aceptar que existe una obligación de obedecer estas normas. Una obligación jurídica de obedecer otra norma jurídica es completamente redundante. Una norma prescribe que es lo que debe o no debe hacerse, y no parece tener sentido suponer que existe otra obligación adicional de hacer lo que las normas señalan que debemos hacer. Por consiguiente, la diferencia entre la obligación que surge de una norma particular y la obligación de obedecer esta norma jurídica no puede consistir en aquello que estamos obligados a hacer sino en el modo en que estamos vinculados por el derecho. Así, Ross sostiene ${ }^{26}$ :

... the idea of a duty to obey the law (to fulfill legal obligations) only makes sense on the supposition that the duty spoken of is a true moral duty corresponding to the 'binding force' inherent in the law.

\footnotetext{
24 John Finnis, Natural Law and Natural Rights, p. 251 (Oxford: Oxford University Press, 1980.

25 Alf Ross, 'Validity and the Conflict between Positivism and Natural Law' reimpreso en Normativity and Norms. Critical Perspectives on Kelsenian Themes, pp. 147-163, Stanley L. Paulson and Bonnie Litschewski Paulson, editores (Oxford: Oxford University Press, 1998).

${ }^{26}$ Alf Ross, 'Validity and the Conflict between Positivism and Natural Law', op. cit., p. 160.
} 
Por esta razón, Ross concluye que la teoría de Kelsen era una forma degenerada de derecho natural, y la explicación de la existencia del derecho no debía hacer referencia a la fuerza vinculante de las normas jurídicas. Finalmente, él concluye ${ }^{27}$ :

It is possible, and highly probable in both the field of law and that of morality, that the usual way of 'thinking' is saturated with ideological concepts that reflect emotional experience but have no function in describing reality, which is the task of legal science. In that case, the job of the analyst is to reject, not to accept, the idea of validity.

La conclusión de Ross es importante: una noción normativa de validez amenaza la separación entre derecho y moral, y por esa razón, no puede ser adoptada por un positivismo coherente. Más aún, atribuir fuerza vinculante a las normas jurídicas también amenaza a la tesis de las fuentes sociales. Dejando de lado el problema de la redundancia señalado anteriormente, hay que advertir que una norma es jurídicamente vinculante cuando los jueces tienen una obligación jurídica de aplicarla a ciertos casos. Esta obligación puede ser concluyente o prima facie. Aún cuando la exigencia normativa fuese sólo prima facie, debemos recordar que, para el positivismo jurídico, las obligaciones jurídicas siempre están determinadas por hechos sociales (i.e. normas positivas). Dado que las obligaciones jurídicas surgen de normas positivas, la existencia de una norma jurídica que impone el deber de obedecer y aplicar otras normas, es un dato contingente. Así, la fuerza vinculante de las normas jurídicas estaría restringida sólo a aquellos sistemas jurídicos que incluya a estas normas positivas. Por esta razón, un positivista que pretenda mantener que siempre existe una obligación jurídica de aplicar las normas jurídicas también necesita socavar la tesis de las fuentes sociales. Esta conclusión es admitida por Neil MacCormick cuando reconoce que 'todo sistema de derecho positivo contienen necesariamente algunas normas no-positivas', y añade que un ejemplo de estas normas es que si una regla es válida y aplicable a un cierto caso, entonces ella debe ser aplicada, a menos que se presenten excepciones implícitas ${ }^{28}$.

Finalmente, algunas veces se señala que el positivista - una vez que ha admitido la fuerza vinculante de las normas- no puede negar que al menos algunas de ellas imponen soluciones concluyentes. En otras palabras, atribuir fuerza vinculante a las normas jurídicas no sólo tendría el inconveniente de socavar la tesis de las fuentes sociales sino también que parece

\footnotetext{
${ }^{27}$ Alf Ross, 'Validity and the Conflict between Positivism and Natural Law', op. cit., p. 161.

${ }^{28}$ Neil MacCormick, 'Natural Law and The Separation of Law and Morals' en Natural Law Theory. Contemporary Essays, p. 121, Robert Georg, editor (Oxford: Oxford University Press, 1992).
} 
conducir al positivismo a un dilema: o bien las normas jurídicas tienen fuerza moral, o bien las normas jurídicas compiten con la moral, ofreciendo justificaciones concluyentes y diferentes a lo que establece la moral. En este sentido, Michael Stokes ha señalado que el positivista debe admitir que mediante la inspección del comportamiento de los miembros del grupo social podemos descubrir cuáles son las normas jurídicas de ese grupo. En caso contrario, existirían normas jurídicas que no tienen su fuente en hechos sociales, y eso llevaría a abandonar una de las tesis centrales del positivismo. Una vez que se concede este punto, según Stoke, hay que admitir también que las normas jurídicas imponen soluciones concluyentes. La razón es que $^{29}$ :

If these laws never provide conclusive answers but must always be supplemented by other standards, we cannot claim that they are the whole of the law. Instead, we must concede that whatever standards and values are used to supplement these laws are also law or we must accept that these laws are not law but are merely, along with the standards used to supplement them, a source of law. Either alternative is inconsistent with the thesis that law has its source in social behaviour.

En resumen: la atribución de fuerza vinculante a las normas parece ser responsable de una crisis en el proyecto positivista. En particular, hay que destacar que una vez que se ha admitido que incluso normas injustas son moralmente vinculantes, se necesitan razones morales para justificar la desobediencia. Sin embargo, ¿por qué debemos aceptar que incluso normas abominables son moralmente vinculantes?. Creo que la única manera de resolver esta dificultad es rechazar la premisa que genera la paradoja, es decir, hay que abandonar la idea de validez como fuerza moral vinculante.

\section{La aplicabilidad de las normas jurídicas}

En esta sección consideraré otro argumento acerca de la conexión entre derecho y moral. Como es bien conocido, algunos antipositivistas, e.g. Lon Fuller, sostienen que no sería posible determinar si una norma se aplica a un cierto caso sin considerar previamente los fines o propósitos que se esperan lograr mediante esa norma, y ello significaría que no es posible trazar una nítida demarcación entre lo que una norma debe regular y lo que ella regula. La identificación de las normas siempre estaría abierta a la discusión acerca de la relevancia de posibles excepciones implícitas que pueden desplazar a la calificación normativa prevista por las autoridades normativas.

\footnotetext{
${ }^{29}$ Michael Stokes, 'Formalism, Realism, and the Concept of Law' en Law and Philosophy 13 (1994), p. 115.
} 
Según este argumento, como dice Jeffrey Goldsworthy ${ }^{30}$, el texto de una ley es sólo una evidencia derrotable de lo que la ley 'realmente' exige, y por esta razón, los tribunales no cambian la ley cuando van más allá de lo que dispone el texto normativo. En este sentido, la tesis de la autodestrucción sería una afirmación acerca de las consecuencias de la interpretación del derecho en el contexto de la aplicación de las normas jurídicas. Las tesis paradójicas serían las siguientes: por una parte, el positivismo afirma que es posible identificar lo que disponen las normas jurídicas sin recurrir a argumentos valorativos, pero el positivismo también admitiría que la interpretación es una etapa inevitable al momento de establecer lo que dispone el derecho en un caso particular. De esta manera, si la interpretación jurídica fuese un proceso inseparable de actividades evaluativas, se seguiría que no es posible identificar lo que las normas jurídicas exigen en un caso individual sin involucrarse en argumentos morales. En otras palabras, habría buenas razones para aceptar que la identificación del derecho depende de consideraciones morales.

Es necesario advertir que esta versión de la tesis de la autodestrucción se basa en dos afirmaciones diferentes. Por una parte, la interpretación del derecho requiere siempre el desarrollo de un argumento moral, y, por otra parte, la interpretación de las normas jurídicas es inevitable para determinar lo que el derecho dispone casos particulares. Es bien conocido que Hart rechaza la primera tesis ${ }^{31}, \mathrm{y}$, sin embargo, su posición acerca de la inevitabilidad de la interpretación no es siempre clara. Veamos este último punto con algún detalle.

Las autoridades jurídicas usualmente formulan sus normas en el lenguaje ordinario de una cierta comunidad. La comunicación entre autoridades y ciudadanos sería imposible si las palabras empleadas por las autoridades no tuviesen instancias claras de aplicación. La regulación del comportamiento mediante normas generales presupone que el significado de las palabras no está indeterminado y, como Hart ha enfatizado, 'es, en verdad, una condición necesaria para la existencia de un sistema jurídico que no toda regla esté abierta siempre a dudas en todos los puntos'32. De otra manera, las normas no servirían como guías de la conducta humana. Sin embargo, Hart recuerda que un margen de indeterminación está ligado a la regulación del comportamiento mediante normas generales. Así, él protesta con-

\footnotetext{
30 Jeffrey Goldsworthy, 'The Self-Destruction of Legal Positivism', Oxford Journal of Legal Studies 10 (1990), p. 471.

${ }^{31}$ See, H.L.A. Hart, 'Positivism and The Separation of Law and Morals', op. cit., pp. 6972.

${ }^{32}$ H.L.A. Hart, The Concept of Law, op. cit., p. 152.
} 
tra la 'aplicación mecánica de las normas' ${ }^{33}$, y concede que la textura abierta del derecho es responsable de la necesidad de la interpretación en, al menos, casos difíciles.

La textura abierta de los conceptos, según Hart, es una consecuencia de dos incapacidades de los seres humanos: el relativo desconocimiento del futuro y la relativa indeterminación de propósitos. Un ser omnisciente no enfrentaría, entonces, problemas de textura abierta. Sin embargo, es conveniente distinguir con claridad entre nuestras capacidades epistémicas y la precisión de nuestro lenguaje. En primer lugar, los límites de nuestro horizonte epistémico no son las únicas fuentes de vaguedad. En algunos casos, decidimos usar conceptos vagos a efectos de otorgar discreción a los interpretes del derecho. Segundo, y más importante, es claro que no toda situación inesperada es una instancia de textura abierta. Las reglas semánticas que fijan el significado de las palabras rara vez son construidas de tal manera de que sólo sirvan para clasificar situaciones sociales que han sido previamente anticipadas. Por supuesto, ello no quiere decir que no existan problemas de vaguedad o que nuestros defectos epistémicos no puedan resultar en problemas de textura abierta, sino más bien intento señalar que no existe una conexión necesaria entre vaguedad y conocimiento. Hart no distingue adecuadamente entre ambas situaciones, y por esa razón señala ${ }^{34}$ :

When the unenvisaged case does arise, we confront the issues at stake and can then settle the question by choosing between the competing interests in the way which best satisfies us. In doing so we shall have rendered more determinate our initial aim, and shall incidentally have settled a question as to the meaning, for the purpose of this rule, of a general word.

Sin embargo, no necesitamos decir que la solución de un nuevo caso siempre hace más preciso el significado de una palabra general. Consideremos un ejemplo famoso. Un grupo de patriotas desea introducir un tanque en un parque con el objetivo de construir un monumento. Supongamos que existe una norma que dispone que no se puede ingresar con vehículos al parque. Finalmente, asumamos que el legislador no ha tenido en cuenta esta situación. Según Hart, al resolver situaciones inesperadas, hacemos dos cosas: decidimos acerca de la calificación normativa de un cierto comportamiento y fijamos el significado de una palabra general. La solución de Hart se apoya en diversas razones, como por ejemplo, la dependencia del lenguaje de nuestras prácticas comunicativas, o la variabilidad del significado asociado a una misma palabra. En este último caso, parece sensato aceptar

${ }^{33}$ H.L.A. Hart, 'Problems of the Philosophy of Law' en Essays in Jurisprudence and Philosophy, op. cit., p. 106.

${ }^{34}$ H.L.A. Hart, The Concept of Law, op. cit., p. 129. 
que la misma palabra 'vehículo' puede tener diferentes significados en una ley sobre seguros y en la norma que intenta preservar la tranquilidad en un parque. El pecado del formalismo consistiría, entonces, en suponer que la misma palabra siempre tiene el mismo significado con independencia del contexto en que ella es introducida. Por consiguiente, parece tentador sostener que las palabras que aparecen en una norma pueden variar de significado según sean los casos que deben ser decididos. Así, parece que nos enfrentamos con un argumento que nos invita a aceptar la siguiente conclusión: dado que una misma palabra puede tener diferentes significados en diferentes formulaciones normativas, también puede suceder que la misma palabra pueda tener diferentes significados en distintos casos que tengamos que resolver. De esta manera, podríamos concluir que el tanque no es un vehículo en el caso anteriormente considerado, pero que si la situación fuese diferente $-\mathrm{y}$ nada impide suponer que las cosas pueden ser diferentes- un tanque sería un vehículo.

Sin embargo, ¿debemos sostener que el tanque no es un vehículo en virtud de que hemos decidido que la norma no se aplica a este caso? Creo que la respuesta debe ser negativa. Como ha señalado Gerald MacCallum ${ }^{35}$ :

In judicial practice, it is very often true that to ask whether the rule applies is to ask whether to apply the rule. (Not surprisingly, applying a rule is like applying a word; considering whether a word applies is very often considering whether to apply the word.) But consider the distinction between the questions (a) Does the rule apply? And (b) Shall I apply the rule? Asking whether the rule applies is asking whether the circumstances of the case fall within the scope of the rule; a judge may know this and yet ask- shall I apply the rule?

Aunque la norma se aplica a ese caso en particular, todavía permanece abierta la cuestión acerca de si las autoridades deben aplicarla. Esta distinción no significa que la misma palabra no pueda tener diferentes significados en distintos contextos, sino más bien que una decisión acerca de su relevancia institucional para resolver un caso no es al mismo tiempo una decisión acerca de su alcance. ¿Por qué deberíamos sostener que, en casos difíciles, una vez que hemos tomado una decisión acerca de la solución del caso, también hemos resuelto la cuestión acerca del significado de una palabra? La explicación más plausible parece ser que los juristas usualmente asumen una conexión normativa entre normas y deberes judiciales. Así, normalmente se presupone que los jueces tienen que aplicar sólo normas aplicables para justificar sus decisiones. De esta manera, se sigue que cuando los jueces no deben aplicar una cierta norma, entonces no puede ser que ella

35 Gerald MacCallum, 'On Applying Rules' en Legislative Intent and Other essays on Law, Politics, and Morality, p. 72, Marcus G. singer and Rex Martin, editors (Madison: The University of Winsconsin Press, 1993). 
regule el caso en cuestión. En otras palabras, si la norma fuese aplicable, entonces ella debería ser aplicada.

Este presupuesto de que los jueces deben aplicar todas y únicamente a las normas aplicables está firmemente arraigado en el pensamiento jurídico, pero nos compromete con una extraña teoría del lenguaje, en la que preferimos decir que las palabras pueden tener un significado episódico (i.e. relativo a casos) antes que reconocer que no hemos aplicado una norma aplicable. Esta conclusión es sólo una versión más débil de la tesis antipositivista que vincula el alcance de una norma a su dimensión justificatoria. En este sentido, Goldsworthy afirma ${ }^{36}$ :

There are cases in which the application of a statutory provision, in strict accordance with the clear meaning of its terms, will produce an absurd or very unjust result, which the legislature can be assumed not to have intended; in such cases, the courts will usually refuse to give that meaning to the provision, holding that the law does not require this.

Como este párrafo pone de manifiesto, la justicia o injusticia del resultado parece ser el criterio final para determinar tanto el significado de una expresión así como también el alcance de una norma jurídica. Un positivista debe resistir esta conclusión, y ello significa que es necesario distinguir entre lo que una norma prescribe y lo que los jueces deben hacer. En el mismo sentido en que hemos distinguido a la validez de la fuerza vinculante, debemos separar la identificación de las normas de su aplicabilidad.

Sin embargo, ¿qué conexiones hay entre normas y casos? No es clara la respuesta que Hart proporciona a esta pregunta. Algunas veces, él concede que 'al aplicar normas jurídicas, alguien debe tomar la responsabilidad de decidir si las palabras cubren el caso en cuestión, con todas sus consecuencias prácticas' ${ }^{37}$. Hart también señala que 'las normas requieren interpretación para ser aplicadas a casos particulares' ${ }^{38}$. Su estrategia es mostrar que las palabras generales a menudo no ofrecen más guía que la que suministra un ejemplo. De esta manera, él trata de refutar al formalismo. Sin embargo, esta actividad interpretativa no se limita a la solución de casos difíciles, sino que juega un papel más importante. Así, Hart señala ${ }^{39}$ :

Rules cannot claim their own instances, and fact situations do not await the judge neatly labelled with the rule applicable to them. Rules cannot provide for

\footnotetext{
36 Jeffrey Goldsworthy, 'The Self-Destruction of Legal Positivism', op. cit., p. 471.

${ }^{37}$ H.L.A. Hart, 'Positivism and the Separation between Law and Morals', op. cit., pp. 6364.

${ }^{38}$ H.L.A., The Concept of Law, op. cit., p. 204.

${ }^{39}$ H.L.A. Hart, 'Problems of the Philosophy of Law' en Essays in Jurisprudence and Philosophy, op. cit., p. 106.
} 
their own application, and even in the clearest case a human being must apply them.

Esta última cita sugiere que entre normas generales y casos individuales hay una 'abismo conceptual', que sólo la interpretación puede salvar. La razón es clara: si la necesidad de interpretar los textos jurídicos es una consecuencia de que los hechos no nos aguardan etiquetados al momento de la aplicación de las normas, entonces es necesario señalar que tanto en casos fáciles así como también en casos difíciles los hechos no ofrecen etiquetas que puedan servir para evitar el proceso interpretativo. No es necesario repetir los argumentos que los escépticos han formulado para mostrar que el derecho está radicalmente indeterminado, es decir, que la aplicación de normas sería -utilizando una conocida expresión de Kripke- un 'salto a ciegas $^{\prime 40}$. En particular, sólo es pertinente recordar que el objetivo de esta versión contemporánea del escepticismo se dirige a mostrar que el proceso interpretativo no puede eliminar la indeterminación del derecho. Dado que la interpretación sería básicamente la sustitución de una regla por otra, entonces nada garantiza que los problemas que surgen al conectar la primera regla con los hechos particulares no reaparezcan al analizar el alcance de la segunda regla. Por tanto, si la interpretación fuese el proceso que nos permite resolver la indeterminación que las normas generales padecen al momento de ser aplicadas a situaciones particulares, entonces no es fácil evitar las objeciones de los escépticos. En otras palabras, si hubiese una brecha conceptual entre normas y hechos, la interpretación no es el puente que nos permita resolver esta situación de indeterminación.

No analizaré, sin embargo, las objeciones del escepticismo radical ya que Hart no sugiere que la interpretación es un proceso necesario a efectos de precisar el alcance de una norma ${ }^{41}$. Una lectura más plausible de sus textos sugiere que Hart enfatiza que la aplicación de normas a casos particulares, al igual que otras acciones, está siempre abierta a evaluación moral. El hecho de que una norma válida regule un caso particular no debe ocultar la responsabilidad moral de decidir este caso. De esta manera, cuando Hart señala que en todo caso -fácil o difícil- es necesario tomar una decisión respecto a si una norma cubre un caso particular no debe entenderse una referencia al proceso de establecer el alcance de una norma. Más bien, lo que se enfatiza es que no es una exigencia de la moral la aplicación mecánica de una regla que puede producir un resultado injusto. Después de todo, si Hart

${ }^{40}$ Saul Kripke, Wittgenstein on Rules and Private Language, p. 55 (Cambridge, Mass: Harvard University Press, 1982).

41 Sobre indeterminación lingüística y escepticismo radical, véase: Timothy Endicott, 'Linguistic Indeterminacy' in Oxford Journal of Legal Studies 16 (1996), pp. 667-697. 
ha replicado a Radbruch afirmando que la pertenencia de una norma a un sistema jurídico no genera consecuencias prácticas, sería incoherente admitir que el hecho de que una norma válida regule un caso genera compromisos morales.

Consideremos, entonces, nuevamente la pregunta: ¿qué conexión hay entre normas y casos? Las normas correlacionan circunstancias abstractas o propiedades con soluciones normativas. Estas propiedades son, a menudo, denominados 'casos', pero ellos son casos genéricos, que no deben confundirse con los casos individuales ${ }^{42}$. Un caso individual es un evento particular que pertenece a un cierto universo del discurso. La diferencia entre ambos tipos de casos es paralela a la distinción entre 'el caso de asesinato político' y el asesinato de John Kennedy. Cuando proyectamos un conjunto de propiedades sobre un cierto universo del discurso, el resultado es una división de ese universo, i.e. unas clases de casos conjuntamente exhaustivas y mutuamente excluyentes. Por esta razón, podemos decir que un caso individual pertenece a uno y sólo uno de los casos genéricos. La solución normativa de todos los casos genéricos también resuelve todos los casos individuales. Por consiguiente, la relación entre normas y casos es interna o conceptual y esto significa que, al igual que la verdad de una proposición, ella no depende de creencias, actitudes o decisiones de los jueces. Aun cuando los jueces deben declarar si un caso individual pertenece a un cierto caso genérico, la relación entre ambos casos no depende de lo que dicen los jueces. El valor de verdad de la proposición 'Bruto mató a Cesar' no depende de la decisión de un juez. El hecho de que una sentencia sea necesaria para dar una solución institucional a un cierto caso individual no significa que ese pronunciamiento del juez también sea una decisión acerca del significado de las palabras.

La conclusión de mi argumento es que necesitamos separar el problema de la identificación del problema de la aplicabilidad de las normas jurídicas. La relación entre normas y sus instancias de aplicación es interna o conceptual, mientras que la relación entre las normas y su relevancia para justificar una decisión institucional es externa o normativa. La relevancia institucional de una norma depende de una serie de factores tales como su relación con otras normas superiores, principios jurídicos, la posición jerárquica del tribunal que resuelve el conflicto, etc. La confusión entre ambos conceptos es bastante frecuente ya que estas distinciones se encuentran enmascaradas por la ambigüedad de la expresión 'norma aplicable'. Así, esta expresión se usa tanto para referirse a los casos que ella regula como tam-

\footnotetext{
${ }^{42}$ Estas distinciones han sido tomadas de Carlos Alchourrón y Eugenio Bulygin, Normative System, p. 28 (Wein-New York: Springer Verlag, 1971).
} 
bién a la norma que debe ser aplicada para justificar una decisión institucional. De esta manera, es natural concluir que las normas que deben ser aplicadas son únicamente aquellas que regulan el caso en cuestión. Sólo cuando ambas nociones de norma aplicable son confundidas surge el problema que señalan los antipositivstas, es decir, la imposibilidad de separar la identificación de una norma de la evaluación de la conveniencia de aplicar la norma en un caso en particular. Pero, si se distingue claramente entre el alcance de una norma y su relevancia, podemos sostener sin incoherencias que una norma jurídica se aplica a un cierto caso y al mismo tiempo que ella no es aplicable. De igual manera, del hecho de que los jueces tengan que aplicar una norma a un cierto caso, no se sigue que ella realmente lo regule.

\section{Punto de vista interno y punto de vista externo}

En mi análisis he procurado evitar la distinción entre punto de vista interno y punto de vista externo. Sin embargo, dado que algunos teóricos pretenden que esta distinción conduce a posiciones antipositivstas, consideraré brevemente otra versión de la tesis de la autodestrucción, que asume que la teoría del derecho es una teoría del derecho que da cuenta de las actitudes de los observadores y los participantes. Jeffrey Goldsworthy defiende esta posición en su interesante trabajo 'The Self-Destruction of Legal Positivism $^{43}$.

La conclusión de Goldsworthy es ${ }^{44}$ :

...the intrinsically normative character of the internal point of view... cannot be reconciled with the primacy which both [Hart and Raz] attribute to law's factual aspect. This ultimately entails the self-destruction of positivism as a participant theory.

Lamentablemente, esta conclusión está infectada por algunas confusiones. En este trabajo sólo me concentraré en algunas distinciones que son necesarias para defender el programa positivista.

En la base del ataque de Goldsworthy encontramos la siguiente tesis: el positivismo jurídico sostiene que, tanto desde el punto de vista interno como del punto de vista externo, el derecho es una cuestión de hechos sociales. Desde un punto de vista externo, decir que una norma jurídica es válida es sostener que ella satisface la regla de reconocimiento de un sistema jurídico. Los observadores (i.e. aquellos situados en el punto de vista externo) describen mediante enunciados externos ciertos hechos sociales com-

\footnotetext{
43 Jeffry Goldsworthy, 'The Self-Destruction of Legal Positivism' en Oxford Journal of Legal Studies 10 (1990).

44 Jeffrey Goldsworthy, 'The Self-Destruction of Legal Positivism', op. cit., p. 452.
} 
plejos, por ejemplo, que una norma ha sido promulgada por una autoridad competente. Pero, ¿qué hacen los participantes -i.e., aquellos que adoptan el punto de vista interno- mediante sus enunciados?, ¿¿Qué dicen ellos mediante los enunciados que afirman que las normas son válidas, y qué es considerado como fundamento de la verdad o falsedad de estos enunciados?' ${ }^{45}$. $\mathrm{Su}$ respuesta es que los participantes demandan obediencia a las normas del sistema, y que estas exigencies son de carácter moral. Así, él escribe ${ }^{46}$ :

A legal official or other person who accepts the legal system from the internal point of view, demands the obedience of all to whom its law apply, whether or not they have agreed to do so, either expressly or tacitly. From the internal point of view the law possesses an authority not claimed by the rules of any game or club, an authority not dependent on its being acknowledged by all concerned. It is doubtful that this kind of authority, and the demands and criticisms which issue from it, can be anything other than moral in nature. (Las cursivas son añadidas)

Parece claro, según esta cita, que los participantes no describen hechos sino que ellos demandan conformidad a ciertos estándares y critican conductas que no satisfacen esas exigencias. Los enunciados internos expresan estas exigencias y críticas, y -según Goldsworthy- éstas son actitudes morales. Antes de considerar la naturaleza moral de estos enunciados, quisiera destacar que no tiene sentido sostener que las exigencias o demandas son verdaderas o falsas. Ellas pueden ser justas, razonables, o eficaces, pero dado que no describen nada, ellas no son verdaderas ni falsas. Por el contrario, los enunciados externos son verdaderos o falsos, y no tiene sentido predicar de ellos obediencia o desobediencia.

La fuente de la confusión de Goldsworthy es la afirmación de que los participantes y los observadores describen los mismos hechos mediante enunciados internos y enunciados externos, respectivamente. Un enunciado externo, por ejemplo, dice que una cierta norma satisface la regla de reconocimiento. Un enunciado interno exige obediencia y expresa actitudes críticas. Por consiguiente no es verdad que ambos enunciados den cuenta de la existencia de los mismos hechos.

Tal vez, Goldsworthy sólo afirma que la diferencia entre participantes y observadores es que ambos manifiestan diferentes actitudes no-cognoscitivas hacia las normas jurídicas. Por ejemplo, según esta interpretación de las afirmaciones de Goldsworthy, cuando los participantes afirman que una norma es válida, ellos no sólo dan cuenta de un cierto hecho contingente, e.g. la relación entre la norma y la regla de reconocimiento sino también ex-

\footnotetext{
45 Jeffrey Goldsworthy, 'The Self-Destruction of Legal Positivism', op. cit., p. 453.

46 Jeffrey Goldsworthy, 'The Self-Destruction of Legal Positivism', op. cit., p. 456.
} 
presan su aceptación de las normas válidas. En este sentido, Hart parece estar de acuerdo con esta estrategia de análisis ya que sostiene ${ }^{47}$ :

I fail to allow for the important distinction between the relatively constant meaning or sense of a sentence fixed by the conventions of language and the varying 'force' or way in which it is put forward by the writer or speaker on different occasions. 'There is a bull in the field' has the same meaning or content whether it is intended by the author as an answer to requests for information or as a warning or hypothesis.

Según esta reconstrucción, el mismo enunciado (e.g. hay una norma válida en el sistema jurídico) puede ser usado descriptivamente o prescriptivamente. Aunque esta estrategia parece atractiva, la solución que ofrece no es convincente. En primer lugar, borra la distinción entre enunciados internos y externos. Dado que la fuerza normativa sólo se expresa mediante factores pragmáticos, no hay diferencia en el nivel de los enunciados. En segundo lugar, y más importante, las actitudes normativas, como demandas y exigencias, muestran compromisos morales solamente cuando las razones que se invocan en apoyo de ellas son de índole moral. Por consiguiente, a efectos de constatar la naturaleza moral de estos enunciados, hay que analizar las actitudes de quienes se encuentran en el punto de vista interno. Sólo en un sistema jurídico patológico el punto de vista interno es adoptado únicamente por sus funcionarios. En sistemas normales, los participantes pueden ser todas aquellas personas que aceptan a las normas jurídicas como pautas de comportamiento. Por ejemplo, supongamos que un abogado aconseja a su cliente para la ejecución de un cierto acto jurídico, e.g. un contrato de leasing. Ella puede decir: 'Hay una norma válida concerniente a las formalidades de este tipo de contratos que no podemos ignorar'. ¿Expresa este enunciado un compromiso moral? Al igual que Hart, creo que la respuesta tiene que ser negativa. Es difícil comprender en qué entido la verdad del enunciado 'existe una norma válida en el sistema jurídico' puede expresar por sí mismo una razón moral. Obviamente, otra razón moral puede otorgar alguna relevancia al hecho de que una norma pertenece a un sistema jurídico. Así, Hart sostiene que 'ningún positivista ... negaría que derechos y obligaciones jurídicas que surgen de principios morales adecuados pueden proporcionar al menos razones morales prima facie para la acción y su aplicación' ${ }^{48}$. Sin embargo, esta es sólo una situación contingente, y este hecho no puede probar que los enunciados internos siempre involucra un compromiso moral.

\footnotetext{
${ }^{47}$ H.L.A. Hart, 'Introduction' en Essays in Jurisprudence and Philosophy, op. cit., pp. 4-5.

${ }^{48}$ H.L.A. Hart, 'Comment to Ronald Dworkin' in Issues in Contemporary Legal Contemporary Legal Philosophy, p. 42 (Oxford: Oxford University Press, 1987).
} 


\section{La justificación de las decisiones judiciales}

Goldsworthy parece creer que los jueces siempre precisan invocar razones morales para justificar sus decisiones institucionales. De esta manera, al menos los enunciados internos de los jueces serían necesariamente de índole moral. Su afirmación está basada parcialmente en su manera de ver la función del razonamiento jurídico. Así, él afirma ${ }^{49}$ :

The function of legal reasoning is to determine when these actions [judicial decisions] are justified, and so the ultimate norms upon which that reasoning is based must somehow be self-justifying.

Desafortunadamente, dado que Goldsworthy no distingue la justificación moral de la justificación jurídica, su conclusión presupone lo que es objeto de debate. Este error de Goldsworthy es bastante frecuente en la filosofía jurídica contemporánea. Dado que se asume que la única justificación posible de las acciones es la que proporcionan las normas morales, se concluye que las normas jurídicas no pueden proporcionar, por ellas mismas, justificación alguna a las decisiones institucionales. En otras palabras, la justificación jurídica sería sólo una 'pseudo-justificación'. De esta manera, lo que tradicionalmente se entiende como 'justificación en derecho' de una decisión institucional sería imposible de analizar para un positivista. Aceptar que la única justificación de acciones y decisiones es la justificación moral conduce a un positivista al siguiente dilema: $\mathrm{O}$ bien, la justificación jurídica sería imposible, o bien se adoptan implícitamente posiciones ideológicas incompatibles con el positivismo conceptual. En el primer caso, la justificación mediante normas jurídicas sería sólo una confusa manera de hablar ya que estas normas carecen de capacidad para otorgar una cualidad moral a las acciones que ellas regulan. En el segundo caso, si se admite que las normas jurídicas justifican decisiones institucionales entonces previamente se ha asumido que esas normas, por el mero hecho de ser jurídicas, tienen un valor moral.

Creo que es necesario rechazar el presupuesto que genera esos problemas, es decir, no se debe admitir sin discusión que la única justificación posible de una acción es la justificación moral. Por supuesto, esto no significa negar que las razones morales son razones últimas o que el razonamiento práctico tiene eventualmente una unidad peculiar. Ésta es una discusión diferente. Aquí sólo interesa señalar que esta subordinación conceptual de las diversas nociones de justificación a la justificación moral sería tan extraña como la propuesta que sostuviese que la noción de bondad moral es la única noción verdadera o correcta de ‘bueno'. De esta manera, se debería

\footnotetext{
49 Jeffrey Goldsworthy, 'The Self-Destruction of Legal Positivism', op. cit., p. 456.
} 
concluir que otras formas de la bondad como técnica o instrumental serían sólo maneras confusas de expresarse, o bien que estas otras nociones de bondad serían sólo 'pseudo-bondades'.

Por supuesto, no existe pecado alguno en reformular los conceptos de la manera que consideramos que tiene mayor utilidad en nuestras reconstrucciones, y no habría inconveniente conceptual en adoptar la propuesta de reducir las diferentes nociones de justificación a la justificación moral. Creo, sin embargo, que es sensato rechazar esta invitación. En primer lugar, la tarea del filósofo no es reformar el lenguaje sino ayudarnos a comprender algunas perplejidades que se generan por una deficiente articulación de intuiciones relevantes. En segundo lugar, el hecho de que reservemos la expresión 'justificación' para la aplicación de normas morales no modificaría la práctica de invocar normas jurídicas como fundamento de las decisiones institucionales. En tercer lugar, la justificación moral de una decisión exige identificar a las normas morales apropiadas, es decir, no basta con la creencia de los jueces en la corrección moral de una norma, sino que, a efectos de justificar su decisión, sus creencias en esa corrección tiene que ser verdadera. Así, a menos que se proporcione un método de decisión para establecer el valor de verdad de las creencias morales, la tesis de la justificación moral sería vacua.

Los antipositivistas suelen responder a estas críticas de la siguiente manera: la naturaleza moral de una norma se identifica por ciertas propiedades que se le atribuyen en el razonamiento práctico, e.g. superviniencia, generalidad, abstracción, etc. De esta manera, continua el argumento, es necesario indagar en la estructura del razonamiento práctico de los jueces si estas normas morales son premisas conceptualmente necesarias para su conclusión. En otro trabajo, he abordado con cierto detalle este argumento y no es necesario repetir aquí los argumentos ${ }^{50}$. Sólo me limitaré a recordar que esta tesis de conexión necesaria entre derecho y moral enfrenta al menos tres dificultades:

En primer lugar, es usual señalar que las premisas de un razonamiento práctico son razones para la acción. Entre estas premisas, es preciso distinguir entre razones operativas y razones auxiliares. Las razones operativas son aquellas que (i) permiten otorgar relevancia práctica a la conclusión y (ii) no son superfluas en un argumento lógicamente concluyente. Una premisa es superflua en un argumento lógicamente concluyente cuando ella no es condición necesaria, suficiente o contribuyente para la conclusión. Una vez que se despliega el razonamiento justificatorio que sugieren los antipo-

50 José Juan Moreso, Pablo E. Navarro y Cristina Redondo, «Argumentación jurídica, lógica y decisión judicial», en Doxa, 11 (1993), pp. 247-262. 
sitivistas se advierte que la norma jurídica y las descripciones de ciertos hechos son condiciones necesarias y suficientes para garantizar la conclusión. Es decir, las 'normas morales', i.e. estas normas últimas, cuya naturaleza moral está asociada a ciertos rasgos formales, son irrelevantes o superfluas desde el punto de vista de un argumento lógicamente concluyente.

La confusión del antipositivista surge de una falta de adecuada distinción entre los elementos conceptuales asociados a los argumentos justificatorios y los aspectos psicológicos inherentes a la aceptación de las normas jurídicas y el proceso de decisión de aplicación de normas. De esta manera, los antipositivstas argumentan que las normas son entidades proposicionales, que sólo pueden ser introducidos en un razonamiento práctico por razones morales. Sin embargo, esto es una confusión entre las razones (i.e. las normas jurídicas) que justifican la conclusión de un argumento y las razones para involucrarse en ese argumento justificatorio (i.e., las razones morales o prudenciales para justificar la aplicación del derecho).

En segundo lugar, estas normas últimas no son necesariamente aquellas normas que una moral crítica identificaría como pautas correctas de comportamiento. Hay que recordar que la principal razón para reducir el concepto de justificación a la noción de justificación moral era la exigencia de no admitir como justificadas ciertas decisiones que podrían ser aberrantes desde el punto de vista moral. Sin embargo, esta conexión entre derecho y moral no puede garantizar esta exigencia. Por el contrario, parece comprometer con la conclusión exactamente opuesta. Dado que la justificación jurídica sería sólo un caso especial de justificación moral, entonces cualquier decisión institucional tendría alguna fuerza moral. Por consiguiente, ahora sería necesario distinguir entre las decisiones justificadas según la moral crítica y aquellas decisiones que están justificadas moralmente simpliciter..

Finalmente, aunque fuese posible dar cuenta de las objeciones señaladas anteriormente, todavía habría que seguir insistiendo en la distinción entre ‘justificación jurídica' y 'justificación moral'. Esta distinción es necesaria para distinguir aquellas decisiones judiciales equivocadas por una aplicación deficiente del derecho, e.g. el juez aplica una norma que se encuentra derogada, de aquellos casos en que los jueces aplican correctamente el derecho. En ambos casos, según la tesis antipositivista, el juez basaría sus decisiones en normas últimas, i.e. 'de naturaleza moral'. Sin embargo, como muestra el ejemplo, todavía sería necesario usar otro criterio que permita distinguir entre decisiones jurídicamente correctas y decisiones arbitrarias.

La noción de justificación jurídica intenta recoger el conjunto de criterios necesarios para dar cuenta de la última objeción que hemos señalado. Por esta razón, es conveniente desde el punto de vista teórico y adecuado con la práctica que se intenta reconstruir, distinguir entre justificación jurí- 
dica y justificación moral. Un positivista rechaza una conexión conceptual entre ambas justificaciones, y es posible sostener que una de las principales funciones del razonamiento jurídico es determinar cuando las acciones institucionales, como las decisiones judiciales, están legalmente justificadas. Para proporcionar una justificación jurídica es completamente irrelevante que se invoque una norma fundamental, que tenga un contenido moralmente evidente. Pero, sin embargo, es preciso invocar una norma jurídica. De igual manera, cuando Goldsworthy afirma que 'más allá de si esas normas fundamentales son consideradas jurídicas, ellas seguramente deben ser normas morales' ${ }^{51}$, un positivista puede responder: 'más allá de si estas normas fundamentales son consideradas morales, ellas seguramente deben ser jurídicas'. Finalmente, mientras Goldsworthy sostiene que 'las normas que son únicamente jurídicas, y no tienen una fuerza extra-jurídica (e.g. fuerza moral), también fracasarían para justificar una acción judicial ${ }^{52}$, la respuesta del positivista podría ser: 'Las normas que tuviesen únicamente cualidad moral, y no tuviesen otra propiedad como por ejemplo, ser jurídicamente válidas, fracasarían para justificar jurídicamente una decisión judicial'.

No intento negar que las normas morales son algunas veces importantes para determinar la validez de las normas jurídicas. Sólo deseo mostrar que la invocación de normas morales por parte de los jueces no juega un papel necesario en la justificación de las decisiones judiciales. Si la justificación jurídica está estrechamente conectada a la validez de las decisiones judiciales, entonces, una reconstrucción positivista parece estar en mejor posición para explicar esta conexión. Las creencias morales de los jueces ( y la calidad moral de las normas que ellos invocan) son irrelevantes en una discusión de la validez de una sentencia. Los sistemas jurídicos no permiten revisar una decisión judicial por el mero hecho de que la sentencia sea moralmente injustificable o porque el juez no comparta la cualidad moral de la norma que ha aplicado. Más aún, esta irrelevancia de las normas morales y las opiniones morales de los jueces contrasta claramente con el hecho de que la principal razón para cuestionar la validez de una sentencia es que carece de un apropiado fundamento jurídico, e.g. no se ha aplicado una norma válida y aplicable que claramente regulaba el caso.

Esta conclusión está lejos de ser una refutación completa de los argumentos de Goldsworthy, pero espero que nos ayude a comprender que la auto-destrucción del positivismo jurídico no se sigue inevitablemente de la distinción entre punto de vista interno y punto de vista externo.

\footnotetext{
51 Jeffrey Goldsworthy, 'The Self-Destruction of Legal Positivism', op. cit., p. 456.

52 Jeffrey Goldsworthy, 'The Self-Destruction of Legal Positivism', op. cit., p. 457.
} 


\section{Conclusiones}

En este trabajo he considerado hasta que punto la tesis de la auto-destrucción amenaza al positivismo jurídico. En particular, he sostenido que los problemas para el positivismo jurídico surgen principalmente de una doctrina que pretende que las normas válidas son moralmente vinculantes. Un enfoque descriptivo del fenómeno jurídico debe resistir la influencia de esta doctrina. Es interesante señalar que algunos antipositivistas consideran inútil esta concepción del positivismo jurídico. Por ejemplo, Dyzenhaus di$\mathrm{ce}^{53}$ :

... it follows that legal positivism...has no role to play in political debates about the role of judges in society. Thus it seems that legal philosophy, at least as conceived by legal positivism, is an even more esoteric pursuit than its critics suppose it to be. It would have, for example, next to nothing to say about debates that rage in England and North America about the appropriate role of judicial review in public law.

No creo que desde las premisas positivistas sea imposible extraer conclusiones interesantes acerca de debates importantes como los que menciona Dyzenhaus ${ }^{54}$. Sin embargo, concederé este punto a los fines de la argumentación. ¿Sería realmente desalentadora esa conclusión? Una buena respuesta a esta pregunta debe advertir que el positivismo jurídico está firmemente anclado en dos tradiciones filosóficas diferentes. Por una parte, el positivismo está ligado a una tradición racionalista y empirista, que conecta la ciencia jurídica a un programa descriptivo y valorativamente neutral. Por otra parte, el positivismo jurídico está vinculado a una tradición política, que enfatiza que el derecho está siempre abierto a cuestionamientos morales. Según la primera tradición, es necesario preservar una estricta separación entre descripción y prescripción, conocimiento y evaluación, ciencia y política. Según la segunda tradición, es necesario resistir que las prescripciones promulgadas por una autoridad eficaz siempre ofrecen una razón moral para la acción. Aun si la filosofía jurídica contemporánea algunas veces parece estar únicamente interesada en esta segunda tradición, es importante remarcar que la primera tradición también merece un cuidadoso análisis. Problemas filosóficos importantes como la estructura jerárquica de los sistemas jurídicos, el carácter dinámico del derecho, o la naturaleza de los sistemas jurídicos son centrales para el esquema conceptual de la ciencia ju-

53 David Dyzenhaus, 'The Legitimacy of Law: A Response to Critics' en Ratio Iuris 7 (1994), p. 81.

${ }^{54}$ Véase, por ejemplo, Joseph Raz, 'On the Authority and Interpretation of Constitutions' en Constitutionalism. Philosophical Foundations, pp. 152-193, Larry Alexander, editor (Cambridge, Cambridge University Press, 1998). 
rídica. La contribución del positivismo jurídico al análisis y solución de estos problemas es difícil de negar. Por consiguiente, aun si fuese verdad que el positivismo jurídico no tuviese nada interesante que decir acerca de problemas como la revisión de la constitucionalidad de las leyes, sería una grosera equivocación concluir que el positivismo no tiene nada interesante que decir acerca de ningún problema de filosofía jurídica.

Mi conclusión es modesta. Principalmente nos recuerda que el conocimiento del derecho es diferente de una respuesta moral a la pregunta sobre la fuerza moral de las normas. La tesis de la auto-destrucción no se sigue de la tesis de la separación conceptual entre derecho y moral o la tesis de las fuentes sociales. Sin embargo, como Hart señaló acerca de otros errores en teoría del derecho ${ }^{55}$, la tesis de la auto-destrucción es a la vez iluminadora y una fuente de perplejidades.. En particular, esta tesis muestra que la tentación de decir 'algo más sustantivo' acerca de la validez jurídica y la existencia de las normas debe ser firmemente resistida por un positivista conceptual. En este sentido, podemos concluir con una afirmación de Michael Hartney acerca de la naturaleza del positivismo jurídico ${ }^{56}$ :

Legal positivism is simply a theory about what counts as law and nothing else: only rules with social sources count as legal rules. It is not a linguistic theory, a moral theory or a theory about judge's moral duties. Some theorists may be legal positivists because they are moral skeptics or utilitarians or political authoritarians or because they believe that all laws are commands, but none of these theories are part of legal positivism.

${ }^{55}$ H.L.A. Hart, The Concept of Law, op. cit., p. 2

56 Michael Hartney: 'Dyzenhaus on Positivism and Judicial Obligation' en Ratio Iuris 7 (1994), p. 49 
$\triangle \quad$ DOXA 24 (2001) 